\title{
Lack of communication kills: Botched circumcisions in the Eastern Cape
}

To the Editor: Xhosa ritual male circumcision in Eastern Cape Province (ECP) has become a matter of significant concern, following the numerous deaths and injuries resulting from botched circumcisions that occur in this cultural practice. Preventing these adverse events is a priority of the Department of Local Government and Traditional Affairs of the Eastern Cape (DLGTA:ECP).

The DLGTA:ECP joined forces with various arms of government and traditional leaders through the Eastern Cape House of Traditional Leaders (ECHTL) to address the problem. In 2011, the ECHTL compiled the Do's and Don'ts of male traditional circumcision for all stakeholders, and then implemented a Monitoring and Intervention Strategy (MIS) on the challenges pertaining to male circumcision.

The objectives of the MIS were to restore the dignity and integrity of ulwaluko (initiation) in the province, to ensure safe passage of young initiates to manhood, to inform and educate key roleplayers about their responsibilities, and to effectively manage stereotypes and perceptions about the male initiation custom. The MIS also involves the deployment of traditional circumcision teams (TCTs) headed by traditional leaders in all districts. The TCTs are responsible for monitoring circumcision huts daily and providing feedback to the ECHTL. The MIS includes pre-initiation preparation ahead of each circumcision season.

Meetings and training workshops on the correct procedure for traditional initiation nursing skills are held for traditional leaders, ingcibi (traditional surgeons) and amakhankatha (traditional nurses) in the province to strengthen the MIS initiative. Dialogue and engagement with ingcibi and amakhankatha are facilitated by the ECHTL and Department of Health to educate the stakeholders.

We undertook a survey to assess whether these initiatives were having an effect. Highlights of our findings were that the MIS, since its inception, has via TCTs rescued 131 illegal initiates who were returned to their home areas in the custody of their parent; identified and reconstructed inadequately built traditional lodges in Bizana, Flagstaff and Lusikisiki; identified initiates in ill-health who subsequently received appropriate clinical intervention; and rescued initiates in Qaukeni and Cofimvaba from natural disasters that took place during the November/December 2011 season, providing alternative lodges and accommodation.

We believe that it is essential for the MIS to not only run seasonally but also to become a proactive and ongoing campaign because, unfortunately, unqualified traditional surgeons, irresponsible parents and inattentive nurses still contribute to the problem of botched 
circumcisions. Regular updating of the database of all traditional surgeons should be maintained and circulated to all stakeholders. Community education and workshops should continue to receive priority.

We thank the Durban University of Technology for funding this study, and the Eastern Cape House of Traditional Healers for their time and input.

\section{Lentsu Nchabeleng \\ Zwakele Ngubane}

Renitha Rampersad

Department of Marketing, Retail and Public Relations

Durban University of Technology

nchabelengl@gmail.com

. Vincent L. Cutting tradition: the political regulation of traditional circumcision rites in South Africa's liberal democratic order. JSAS 2008;34:77-91. [http://dx.doi.org/10.1080/03057070701832890]

2. Stinson K. Male circumcision in South Africa: how does it relate to public health? http://www. africanvoices.co.za/culture/circumcision.htm (accessed 12 March 2010).

3. Meintijes G. Manhood at a price: socio-medical perspectives on Xhosa traditional circumcision Grahamstown: Rhodes University, 1998:7-12.

4. Melkote SR, Steeves HL. Development for communication in the third world: theory and practice for empowerment. California: Sage Publishing, 2001.

5. McPhail TL. Development communication. Chichester: Wiley-Blackwell, 2009:3-12.

S Afr Med J 2012;102(12):896-897. DOI:10.7196/SAMJ.6343 